\title{
Dimensionamento da alvenaria estrutural em situação de incêndio: contribuição à futura normatização nacional
}

\author{
Design of masonry walls in situations of fire: $a$ \\ contribution for a future Brazilian standard
}

\section{Helena Arias Lara Leite Armando Lopes Moreno Júnior Daniel Luis Torres}

\section{Resumo

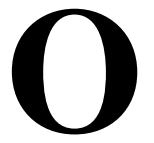

Brasil carece de uma legislação sobre alvenaria estrutural em situação de incêndio. Por conta disso, o Corpo de Bombeiros do Estado de São Paulo (2011) recomenda que se faça esse dimensionamento de acordo com as recomendações do Eurocode 6 (2005) ou norma internacional similar. Com o intuito de subsidiar futuras discussões sobre uma normatização nacional, neste artigo são apresentados os procedimentos de dimensionamento da alvenaria estrutural em situação de incêndio em vigor nos Estados Unidos, na Europa e na Austrália. Ao final, sem deixar ao largo o questionamento da aplicabilidade dessas três normas à situação brasileira, por conta das diferenças de materiais utilizados tanto nos blocos quanto nos acabamentos, sugere-se mesclar o que há de interessante nesses três códigos internacionais, de forma gradativa, na elaboração de futura norma brasileira sobre o assunto.

Palavras-chaves: Alvenaria estrutural. Incêndio. Norma. Resistência ao fogo.

Helena Arias Lara Leite Universidade Estadual de Campinas Campinas - SP - Brasil

Armando Lopes Moreno Junior Universidade Estadual de Campinas Campinas - SP - Brasil

Daniel Luis Torres Universidade Estadual de Campinas Campinas - SP - Brasil

Recebido em 22/05/15 Aceito em 01/12/15

\section{Abstract}

In Brazil, there is no standard regarding the design of masonry walls in fire situations. According to the Fire Department of the state of São Paulo (2011), either the Eurocode 6 (2005) or an equally recognized international Standard should be used in such a situation. In this article, design specifications for masonry walls in situation of fire are presented, according to the standard requirements in the United States of America, Europe and Australia. One might question the applicability of these codes in the Brazilian context, due to the different materials the structural units are made of and the rendering applied on the walls. Taking that into account, we suggest that the applicable elements of the three international standards should be gradually integrated into the development of a Brazilian standard.

Keywords: Masonry. Fire. Standard. Fire resistance.

LEITE, H. A. L.; MORENO JÚNIOR, A. L.; TORRES, D. L. Dimensionamento da alvenaria estrutural em situação de 


\section{Introdução}

A resistência ao fogo é a capacidade de um elemento estrutural permanecer exercendo as funções para as quais foi projetado durante um determinado tempo, sob as circunstâncias de um incêndio.

De modo geral, os procedimentos adotados de dimensionamento de um elemento estrutural em situação de incêndio, englobam a verificação da resistência mecânica $(R)$, da estanqueidade $(E)$ e do isolamento térmico (I). Para obedecer a esses critérios, a estrutura não deve alcançar a ruptura, não deve apresentar trincas ou aberturas suficientes que permitam a passagem de gases ou chamas e não deve apresentar um aumento de temperatura, na face não exposta, acima da temperatura inicial, superior em média a $140^{\circ} \mathrm{C}$ e em qualquer ponto a $180^{\circ} \mathrm{C}$.

Quanto ao tempo em que a edificação deve se manter resistente ao fogo, deve-se ater a limites estabelecidos, a consenso na sociedade, que garantam a fuga dos ocupantes da edificação em condições de segurança, que garantam a segurança das operações de combate ao incêndio e que minimizem danos a edificações adjacentes e à infraestrutura pública (padronizados nacionalmente pela NBR 14432 (ABNT, 2001)).

Para a alvenaria empregada como estrutura, é importante observar que, quase sempre, as paredes devem atender aos três critérios básicos para o dimensionamento de estruturas em situação de incêndio. Entretanto, nacionalmente, talvez pela inexistência de procedimentos normatizados de dimensionamento, o que se observa, até então, é que a questão estrutural $(\mathrm{R})$ tem sido colocada em segundo plano, atendo-se somente, quando existentes, às verificações de isolamento térmico (I) e de estanqueidade (E). A questão estrutural não deve ser vista como um item menos importante, pois a estrutura da edificação não deve alcançar a ruptura durante a citada fuga dos usuários.

A normatização nacional sobre o dimensionamento de estruturas em situação de incêndio é bem atual. Destacam-se a NBR 15200 (ABNT, 2012) Projeto de estruturas de concreto em situação de incêndio, a NBR 14432 (ABNT, 2001) Exigências de resistência ao fogo de elementos construtivos e a NBR 14323 (ABNT, 2013) Projeto de estruturas de aço e de estruturas mistas de aço e concreto de edifícios em situação de incêndio. Quanto à alvenaria estrutural em situação de incêndio, ainda não existe normatização nacional sobre o assunto. Tal fato justifica a recomendação do Corpo de Bombeiros do Estado de São Paulo, em sua Instrução Técnica 08/2011 (POLÍCIA..., 2011), de que seja empregado o Eurocode 6 (EUROPEAN..., 2005) ou norma similar reconhecida internacionalmente.

Com o intuito de subsidiar futuras discussões sobre uma normatização nacional, neste artigo são apresentados os procedimentos de dimensionamento da alvenaria estrutural em situação de incêndio em vigor nos Estados Unidos, na Europa e na Austrália.

\section{Comportamento da alvenaria estrutural em situação de incêndio}

A alvenaria estrutural é composta por elementos de alvenaria (blocos cerâmicos ou de concreto), argamassa de assentamento, eventual armadura de aço e eventual revestimento (acabamentos). O comportamento resistente ao fogo da alvenaria estrutural depende, logicamente, do comportamento resistente a elevadas temperaturas de cada um desses materiais, isoladamente e em conjunto.

Nacionalmente, ainda se caminha a passos lentos na avaliação do comportamento da alvenaria estrutural em situação de incêndio. Pouco se conhece, no país, sobre as propriedades térmicas e mecânicas, sob temperaturas elevadas, dos materiais componentes da alvenaria estrutural. Da mesma forma, quando se avalia resultados existentes sobre o comportamento de paredes de alvenaria em situação de incêndio, nota-se, além da insignificância numérica de resultados nacionais, a inexistência de resultados de paredes avaliadas sob carga.

Rosemann (2011) ensaiou paredes de alvenaria cerâmica quanto ao isolamento térmico, não carregadas, alternando a presença de revestimentos de argamassa e o preenchimento dos vazios com areia. $\mathrm{O}$ autor constatou que as paredes sem revestimento e sem preenchimento apresentaram resistência ao fogo de 106 minutos. Com a aplicação de revestimento de argamassa nas faces da parede, obteve-se um aumento de $80 \%$ na resistência ao fogo e, com o preenchimento com areia nos principais vazios dos blocos, o acréscimo verificado foi de $100 \%$. Constatou-se, portanto, que o emprego de revestimentos nas faces e o preenchimento dos vazios com areia representam boas alternativas, a um custo relativamente baixo, para aumentar a resistência ao fogo de paredes de alvenaria cerâmica. 
Rigão (2012) ensaiou pequenas paredes carregadas de alvenaria cerâmica (com restrição de deslocamento na vertical). Ele constatou que, em relação às argamassas, temperaturas de $900^{\circ} \mathrm{C}$ são suficientes para promover sua completa deterioração e que o tipo de agregado nela utilizado tem influência na perda de massa e estabilidade do material. Vale ressaltar que, nos ensaios feitos por esse autor, a taxa de aquecimento do forno não seguiu a curva de incêndio-padrão (INTERNATIONAL..., 1999). Em relação às paredes, foi constatado que houve, no transcorrer do ensaio, devido ao gradiente térmico e à restrição de deslocamento vertical imposta, um aumento de carga considerável. Também se constatou que, em todas as paredes, houve um atraso, a partir do início do ensaio, de aproximadamente 20 minutos, de início do incremento de carga mencionado. Tal atraso ocorreu porque, durante o período inicial do ensaio, as temperaturas do meio da parede e de sua face não aquecida mantiveram-se praticamente inalteradas e, portanto, ainda não haviam tensões térmicas significativas na parede.

Internacionalmente, embora muito poucos quando comparados aos existentes para o aço ou para o concreto armado, existem pesquisadores interessados no comportamento da alvenaria estrutural em situação de incêndio. A seguir, serão citados resultados observados por alguns deles.

Bailey (2004) afirma que o colapso de uma parede de alvenaria em situação de incêndio, quando ocorre, é geralmente devido aos carregamentos impostos pelas deformações das estruturas ou elementos estruturais adjacentes a ela. $\mathrm{O}$ autor ainda lembra que não se deve extrapolar os resultados de ensaios em paredes com menos de três metros de altura para paredes maiores, pois, neste último caso, seu deslocamento lateral a meiaaltura cresceria devido ao efeito da curvatura térmica e, portanto, elas colapsariam antes de paredes com alturas menores ou iguais a três metros.

Nadjai et al. (2006) lembram que estruturas de grandes dimensões são raramente alvos de experimentos, por conta do custo e das limitações físicas dos equipamentos existentes (fornos). Portanto, há pouca evidência experimental relacionando a resistência ao fogo de elementos individuais (blocos ou prismas) à resistência ao fogo da parede. Simulações numéricas apresentamse como uma solução para as limitações que existem nos experimentos quanto ao tamanho da amostra.

Para Nadjai et al. (2006), em elementos de compartimentação, como paredes de alvenaria, o fogo está geralmente em apenas um lado. A parede irá, portanto, curvar-se, devido à expansão térmica diferencial. Esse fato, juntamente com a degradação das propriedades dos materiais, que se inicia em seu lado exposto ao fogo, pode resultar no colapso estrutural da parede, que depende das condições de vinculação de seus apoios, da magnitude de carga nela aplicada e de sua geometria.

Segundo Ingham (2009), sob temperaturas baixas para um incêndio, da ordem de $250^{\circ} \mathrm{C}$ a $300{ }^{\circ} \mathrm{C}$, os danos às paredes de alvenaria ficam geralmente restritos às mudanças de cor, como por exemplo, o avermelhamento de rochas e argamassas compostas por ferro. Entretanto, com a elevação da temperatura, uma parede de alvenaria estrutural sofrerá uma redução progressiva em sua resistência à compressão, por conta, principalmente, da deterioração da argamassa de assentamento. A temperaturas elevadas, entre $600^{\circ} \mathrm{C}$ e $800^{\circ} \mathrm{C}$, a resistência à compressão da maioria das rochas e argamassas é seriamente comprometida.

Ingham (2009) ainda faz um alerta sobre o eventual colapso das paredes de alvenaria estrutural durante eventual resfriamento com água (o que é usual nas operações de combate ao incêndio). Ao se resfriar com água a alvenaria aquecida pelo fogo, o choque térmico e eventual contração do material pelo resfriamento fazem com que ocorra um intenso panorama de fissuração na parede, com muitas fissuras e bastante abertas, o que pode colaborar, naturalmente, para o colapso da parede.

Ingham (2009) avisa sobre o provável lascamento explosivo de alguns tipos de blocos cerâmicos quando em situação de incêndio, principalmente os que não são maciços.

Para Ingham (2009), estruturas de alvenaria de pedra ou cerâmica podem ser seriamente afetadas por incêndios. O dano tende a ficar concentrado ao redor de aberturas de portas e janelas, porém nada impede que o mesmo ocorra em outras regiões da parede ou mesmo que seja causado pela expansão ou colapso de outros elementos estruturais de edificação, próximos ou conectados à parede de alvenaria.

Andreini e Sassu (2011) são dois pesquisadores que defendem o bom comportamento da alvenaria em situação de incêndio. Mencionam que grande parte do interesse pela construção em alvenaria se deve à capacidade desse material de isolar um ambiente tanto do fogo em si quanto dos efeitos da fumaça (servindo, então, como paredes de compartimentação). Os autores ainda ressaltam o excelente comportamento, sob elevadas temperaturas, da argamassa de assentamento e de 
blocos de alvenaria feitos com argila ou concreto com agregados leves.

Nguyen e Meftah (2012) lembram que a resistência ao fogo da maioria das paredes de alvenaria pode ser determinada através de ensaios em laboratório ou por métodos semi-empíricos que, por sua vez, são quase sempre muito conservadores, resultando em estruturas mais caras. Uma alternativa, segundo os mesmos autores, seria adotar um modelo de cálculo baseado em modelagem computacional avançada; sendo possível, nesse caso, a consideração de cenários específicos de incêndios, geometrias diferentes das padronizadas e processos complexos de degradação dos materiais, como o lascamento explosivo.

Nguyen e Meftah (2012) ressaltam, ainda, que modelos numéricos sofisticados requerem resultados experimentais específicos para obter dados quanto às propriedades mecânicas e térmicas dos materiais. Resultados de ensaios usuais de caracterização dos materiais podem ser insuficientes para validar uma simulação numérica avançada. Em seu trabalho, os autores ensaiaram quatro paredes de alvenaria e chegaram a algumas conclusões gerais importantes: em paredes grossas (de espessura maior que $12-14 \mathrm{~cm}$ ) e estruturais, pode ocorrer lascamento explosivo, o qual não se propaga por toda a espessura da parede e, portanto, não interfere em sua resistência mecânica. O critério-chave para o dimensionamento da parede continuará a ser o isolamento térmico (I).

Em outro trabalho recente, Nguyen e Meftah (2014), relatam que a alvenaria de blocos cerâmicos ainda ocupa uma parcela importante no mercado de construção civil em diversos países, pois apresenta soluções construtivas de baixo custo. Propõem blocos de alvenaria cada vez mais resistentes ao fogo como soluções para melhorar a resistência ao fogo do conjunto (parede).

Nguyen e Meftah (2014) ressaltam que modelos bidimensionais podem até simular satisfatoriamente o comportamento ao fogo de paredes de alvenaria estrutural de blocos cerâmicos. Entretanto, em paredes onde o lascamento explosivo tem grande probabilidade de ocorrência, como é o caso de paredes estruturais feitas com blocos vazados, a ruptura local é um fator importante que governa o comportamento ao fogo da alvenaria e, portanto, não deve ser ignorada em simulações numéricas.

Após a apresentação dos resultados de pesquisa envolvendo a alvenaria estrutural sob elevadas temperaturas, ressalta-se, mais uma vez, a importância da normatização nacional para procedimentos de dimensionamento desse material em situação de incêndio. Tais procedimentos devem ser discutidos à luz de aspectos voltados ao sistema construtivo e materiais de uso corrente em nosso país. A seguir, serão expostas as recomendações para dimensionamento de alvenaria estrutural em situação de incêndio no Brasil e no exterior.

\section{Recomendações nacionais de dimensionamento da alvenaria estrutural em situação de incêndio}

$\mathrm{Na}$ inexistência de um código nacional sobre o dimensionamento de alvenaria estrutural em situação de incêndio, o meio técnico, como referência, costuma ter por base algumas publicações já tradicionais no setor. Pode-se citar, por exemplo, o Manual Técnico de Alvenaria (ASSOCIAÇÃO..., 1990), onde são apresentados resultados de alguns ensaios realizados em paredes de alvenaria estrutural segundo a NBR 5628. A partir dos resultados obtidos, as paredes de alvenaria, executadas com diferentes blocos estruturais, foram categorizadas em corta-fogo (enquanto atenderem aos requisitos de resistência mecânica, estanqueidade e isolamento térmico), para-chamas (enquanto atenderem aos requisitos de resistência mecânica e estanqueidade) e estável ao fogo (enquanto atenderem apenas ao requisito de resistência mecânica).

A Tabela 1 apresenta os valores divulgados na citada referência.

Durante muito tempo, a tabela anterior foi uma das únicas referências nacionais para a verificação da alvenaria estrutural em situação de incêndio.

Pode-se citar também o Manual de Desempenho para Alvenaria de Blocos de Concreto da Associação Brasileira de Cimento Portland e Associação Brasileira da Indútria de Blocos de Concreto (2014), onde são apresentados resultados de ensaios de pequenas paredes de alvenaria com e sem revestimento e concluiu-se que elas podem ser consideradas como corta-fogo, pois resistiram a uma temperatura de $900^{\circ} \mathrm{C} \pm 5^{\circ} \mathrm{C}$ por um tempo superior a $240 \mathrm{~min}$ (4 horas). No entanto, essas paredes foram ensaiadas sem carga e suas dimensões não atenderam às mínimas previstas em norma nacional de parede quanto ao tamanho de corpo de prova.

Outra referência nacional importante na verificação da alvenaria estrutural em situação de incêndio é a Instrução Técnica 08/2011 (IT-08) Resistência ao Fogo dos Elementos de Construção, do Corpo de Bombeiros do Estado de São Paulo 
((POLÍCIA..., 2011), que, em seu anexo B, mostra resultados de alguns ensaios realizados em paredes de alvenaria. A Tabela 2 reproduz os resultados.

Quanto à falta de normatização nacional sobre o assunto, a IT-08 do Corpo de Bombeiros do Estado de São Paulo (POLÍCIA..., 2011) explica ainda que, nesse caso, devem ser seguidas as recomendações do Eurocode 6 (EUROPEAN..., 2005) ou de norma similar reconhecida internacionalmente. Entretanto, uma ressalva a essa recomendação deve ser feita. Deve ser questionada a aplicabilidade de normas internacionais à realidade nacional uma vez que a geometria de blocos pode variar de país para país, conforme o exemplo mostrado nas Figuras 1 e 2, e os materiais utilizados, tanto nos blocos quanto nos revestimentos, também apresentam divergências, de país para país, em relação às suas propriedades térmicas e mecânicas.

\section{Código americano: ACI/TMS 216.1-14 (2014)}

Este código normativo apresenta procedimentos de dimensionamento de estruturas de concreto e de alvenaria em situação de incêndio. As paredes de alvenaria estrutural são verificadas em função da garantia de valores mínimos para a espessura efetiva das paredes. A espessura equivalente mínima é determinada em função do tipo de elemento de alvenaria (bloco) e do tempo requerido de resistência ao fogo. No cálculo da espessura efetiva são considerados parâmetros como o tipo de acabamento e a configuração de vazios do bloco.

\section{Espessura equivalente mínimas das paredes}

As espessuras equivalentes mínimas das paredes, pilares e vergas de alvenaria de blocos de concreto e para as paredes de blocos cerâmicos, necessárias para tempos de resistência ao fogo de 0,5 a 4 horas, são apresentadas, respectivamente, nas Tabelas 3, 4, 5 e 6 . A Figura 3 mostra um esquema de pilar de alvenaria armada, para um melhor entendimento da Tabela 4.

Tabela 1 - Resistência ao fogo de blocos de concreto e cerâmico

\begin{tabular}{c|c|c|c|c|c}
\hline \multirow{2}{*}{ Bloco } & \multirow{2}{*}{$\begin{array}{c}\text { Espessura } \\
(\mathbf{c m})\end{array}$} & Revestimento & \multicolumn{3}{|c}{ Características } \\
\cline { 3 - 6 } & 19 & $\begin{array}{c}\text { Argamassa } 2 \mathrm{~cm} \text { na face exposta ao } \\
\text { fogo }\end{array}$ & $\begin{array}{c}\text { Para } \\
\text { chamas }\end{array}$ & $\begin{array}{c}\text { Estável ao } \\
\text { fogo }\end{array}$ \\
\hline Concreto vedação & 14 & - & - & - \\
\hline Concreto estrutural & 9 & 1,5 em cada face & $1,5 \mathrm{~h}$ & $2 \mathrm{~h}$ & $2 \mathrm{~h}$ \\
\hline Cerâmico vedação & 14 & Gesso $3 \mathrm{~mm}$ na face exposta ao \\
fogo & $2 \mathrm{~h}$ & $4 \mathrm{~h}$ & $4 \mathrm{~h}$ \\
\hline Cerâmico estrutural & 14 & - & $1,5 \mathrm{~h}$ & $2 \mathrm{~h}$ & $2 \mathrm{~h}$ \\
\hline Cerâmico estrutural & 14 & $1,5 \mathrm{~cm}$ em cada face & $2 \mathrm{~h}$ & $3 \mathrm{~h}$ & $3 \mathrm{~h}$ \\
\hline Cerâmico estrutural & 14 &
\end{tabular}

Fonte: adaptado de $\mathrm{ABCI}$ (ASSOCIAÇÃO..., 1990, p. 140).

Tabela 2 - Resistência ao fogo para alvenarias

\begin{tabular}{|c|c|c|c|c|c|c|}
\hline \multirow{2}{*}{\multicolumn{2}{|c|}{ Paredes ensaiadas }} & \multirow{2}{*}{$\begin{array}{l}\text { Espessura do } \\
\text { revestimento } \\
(\mathrm{cm})\end{array}$} & \multirow{2}{*}{$\begin{array}{c}\text { Duração } \\
\text { do ensaio } \\
\text { (min) }\end{array}$} & \multicolumn{3}{|c|}{$\begin{array}{l}\text { Tempo de atendimento aos critérios de } \\
\text { resistência ao fogo (horas) }\end{array}$} \\
\hline & & & & Integridade & Estanqueidade & $\begin{array}{c}\text { Isolamento } \\
\text { térmico }\end{array}$ \\
\hline \multirow{4}{*}{$\begin{array}{c}\text { Tijolos de } \\
\text { barro } \\
\text { cozido }\end{array}$} & $\begin{array}{l}\text { Meio tijolo sem } \\
\text { rev. }\end{array}$ & - & 120 & $\geq 2$ & $\geq 2$ & $11 / 2$ \\
\hline & Um tijolo sem rev. & - & 395 & $\geq 6$ & $\geq 6$ & $\geq 6$ \\
\hline & $\begin{array}{l}\text { Meio tijolo com } \\
\text { rev. }\end{array}$ & 2,5 & 300 & $\geq 4$ & $\geq 4$ & 4 \\
\hline & Um tijolo com rev. & 2,5 & 300 & $\geq 6$ & $\geq 6$ & $\geq 5$ \\
\hline \multirow{4}{*}{$\begin{array}{c}\text { Blocos } \\
\text { vazados de } \\
\text { concreto (2 } \\
\text { furos) } \\
\end{array}$} & $14 \mathrm{~cm}$ sem rev. & - & 100 & $\geq 1,5$ & $\geq 1,5$ & $11 / 2$ \\
\hline & $19 \mathrm{~cm}$ sem rev. & - & 120 & $\geq 2$ & $\geq 2$ & $11 / 2$ \\
\hline & $14 \mathrm{~cm}$ com rev. & 1,5 & 150 & $\geq 2$ & $\geq 2$ & 2 \\
\hline & $19 \mathrm{~cm}$ com rev. & 1,5 & 185 & $\geq 3$ & $\geq 3$ & 3 \\
\hline \multirow{2}{*}{$\begin{array}{c}\text { Tijolos } \\
\text { cerâmicos } \\
\text { de } 8 \text { furos }\end{array}$} & Meio tijolo com rev. & 1 & 150 & $\geq 2$ & $\geq 2$ & 2 \\
\hline & Um tijolo com rev. & 1 & 300 & $\geq 4$ & $\geq 4$ & $\geq 4$ \\
\hline
\end{tabular}

Fonte: adaptado de IT-08 (POLíCIA..., 2011, p. 199). 
Figura 1 - Geometria da seção transversal do cerâmico estrutural brasileiro

Dimensões em milímetros

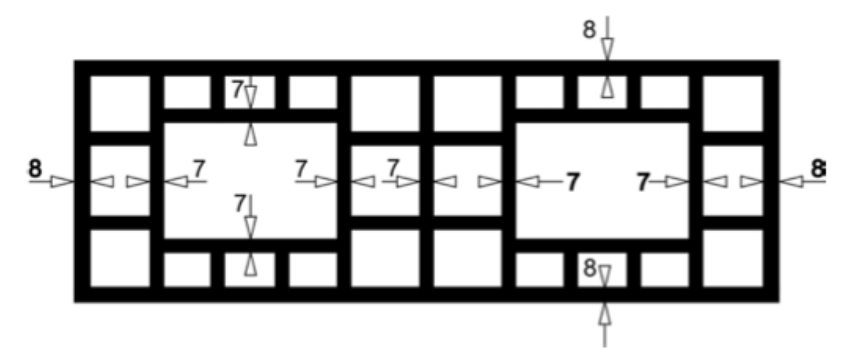

Fonte: NBR 15270-2 (ABNT, 2005, p. 6).

Figura 2 - Geometria da seção transversal de blocos cerâmicos estruturais americanos
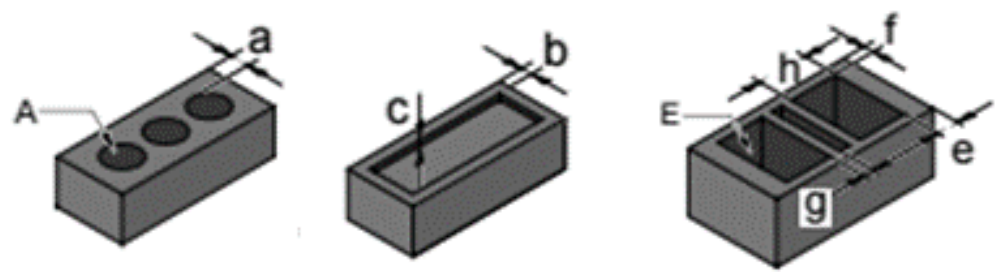

Fonte: Brick Industry Association (2015).

Tabela 3 - Paredes de alvenaria de blocos de concreto

\begin{tabular}{|c|c|c|c|c|c|c|c|}
\hline \multirow[b]{2}{*}{$\begin{array}{l}\text { Tipo de agregado } \\
\text { empregado no Bloco }\end{array}$} & \multicolumn{7}{|c|}{$\begin{array}{c}\text { Mínima espessura equivalente } \mathbf{T}_{\text {ea }} \text {, em função do tempo } \\
\text { requerido de resistência ao fogo }(\mathrm{cm}) * * *\end{array}$} \\
\hline & $\begin{array}{c}1 / 2 \\
\text { hora }\end{array}$ & $\begin{array}{c}3 / 4 \\
\text { hora }\end{array}$ & 1 hora & $\begin{array}{c}11 / 2 \\
\text { horas }\end{array}$ & 2 horas & 3 horas & 4 horas \\
\hline Cascalho de calcário ou silício & 5,1 & 6,1 & 7,1 & 9,1 & 10,7 & 13,5 & 15,7 \\
\hline $\begin{array}{l}\text { Pedra calcária, cinzas ou } \\
\text { escória resfriada a ar }\end{array}$ & 4,8 & 5,8 & 6,9 & 8,6 & 10,2 & 12,7 & 15,0 \\
\hline $\begin{array}{c}\text { Argila expandida, xisto } \\
\text { expandido ou ardósia } \\
\text { expandida }\end{array}$ & 4,6 & 5,6 & 6,6 & 8,4 & 9,1 & 11,2 & 13,0 \\
\hline $\begin{array}{l}\text { Escória expandida ou pedra- } \\
\text { pomes }\end{array}$ & 3,8 & 4,8 & 5,3 & 6,9 & 8,1 & 10,2 & 11,9 \\
\hline
\end{tabular}

Nota: *resistências entre os períodos listados devem ser determinadas por meio de interpolação linear baseada na espessura equivalente da parede de alvenaria de concreto; e

** Espessuras mínimas equivalentes correspondentes à resistência ao fogo para blocos feitos com combinações de

agregados devem ser determinadas por interpolação linear, baseada na porcentagem do volume de cada agregado utilizado em sua fabricação.

Fonte: ACI/TMS 216.1-14 (AMERICAN..., 2014, p. 21) (convertida para cm).

Tabela 4 - Pilares de alvenaria armada

\begin{tabular}{c|c|c|c|c}
\hline Resistência ao fogo, horas & $\mathbf{1}$ & $\mathbf{2}$ & $\mathbf{3}$ & $\mathbf{4}$ \\
\hline $\begin{array}{c}\text { Dimensões nominais mínimas do pilar } \\
(\mathbf{c m}) *\end{array}$ & 20,3 & 25,4 & 30,5 & 35,6 \\
\hline
\end{tabular}

Nota: *cobrimento da armadura: 5,1 cm.

Fonte: ACI/TMS 216.1-14 (AMERICAN..., 2014, p. 21) (convertida para cm). 
Figura 3 - Esquema de pilar de alvenaria armada

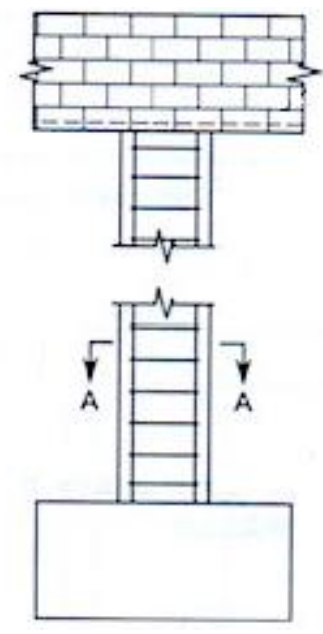

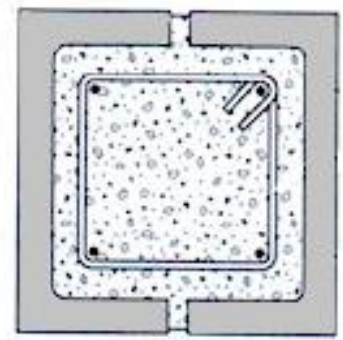

Corte A-A

Fonte: Charalambides (2015).

Tabela 5 - Vergas de alvenaria armada

\begin{tabular}{c|c|c|c|c}
\hline \multirow{2}{*}{$\begin{array}{c}\text { Espessura } \\
\text { nominal das } \\
\text { vergas (cm) }\end{array}$} & \multicolumn{4}{|c}{$\begin{array}{c}\text { Espessura mínima necessária do cobrimento } \\
\text { da armadura para resistir ao tempo } \\
\text { especificado (cm) }\end{array}$} \\
\cline { 2 - 5 } & 1 hora & 2 horas & 3 horas & 4 horas \\
\hline 15,2 & 3,8 & 5,1 & NP & NP \\
20,3 & 3,8 & 3,8 & 4,4 & 7,6 \\
25,4 ou mais & 3,8 & 3,8 & 3,8 & 4,4 \\
\hline
\end{tabular}

Nota: NP = Não permitido sem uma análise mais detalhada.

Fonte: ACI/TMS 216.1-14 (ASSOCIATION..., 2014, p. 21) (convertida para cm).

Tabela 6 - Paredes de alvenaria de blocos cerâmicos

\begin{tabular}{|c|c|c|c|c|}
\hline \multirow[t]{2}{*}{ Tipo de material } & \multicolumn{4}{|c|}{$\begin{array}{l}\text { Mínima espessura equivalente } T_{\text {ea }} \text {, em função do } \\
\text { tempo requerido de resistência ao fogo }(\mathrm{cm})^{*}\end{array}$} \\
\hline & 1 hora & 2 horas & 3 horas & 4 horas \\
\hline $\begin{array}{c}\text { Tijolo maciço de barro ou } \\
\text { xisto }\end{array}$ & 6,9 & 9,7 & 12,4 & 15,2 \\
\hline $\begin{array}{l}\text { Bloco vazado ou telha de } \\
\text { barro ou xisto, sem } \\
\text { preenchimento }\end{array}$ & 5,8 & 8,6 & 10,9 & 12,7 \\
\hline $\begin{array}{l}\text { Bloco vazado ou telha de } \\
\text { barro ou xisto, grauteada ou } \\
\text { preenchido com materiais } \\
\text { específicos }\end{array}$ & 7,6 & 11,2 & 14,0 & 16,8 \\
\hline
\end{tabular}

Nota: *cálculos entre as horas tabeladas devem ser determinados por interpolação linear.

Fonte: ACI/TMS 216.1-14 (ASSOCIATION..., 2014, p. 27) (convertida em cm).

\section{Espessura equivalente das paredes de alvenaria $\left(T_{e a}\right)$}

A espessura equivalente de uma parede de alvenaria, $\mathrm{T}_{\text {ea }}$, é a soma entre a espessura equivalente do bloco, $\mathrm{T}_{\mathrm{e}}$, e a espessura equivalente de seu acabamento, $\mathrm{T}_{\text {ef. }}$. Ou seja (Eq. 1):

$T_{e a}=T_{e}+T_{e f}$
Onde:

$\mathrm{T}_{\mathrm{ea}}=$ espessura equivalente de uma parede de alvenaria;

$\mathrm{T}_{\mathrm{e}}=$ espessura equivalente do bloco; $\mathrm{e}$

$\mathrm{T}_{\mathrm{ef}}=$ espessura equivalente do acabamento. 


\section{Determinação da espessura equivalente do bloco $\left(T_{e}\right)$}

A espessura equivalente do bloco é tomada como (Eq. 2):

$T_{e}=\frac{V_{n}}{L H}$

Onde:

$\mathrm{V}_{\mathrm{n}}=$ volume líquido do bloco;

$\mathrm{L}=$ comprimento do bloco; $\mathrm{e}$

$\mathrm{H}=$ altura do bloco.

Paredes não grauteadas ou parcialmente grauteadas: a espessura equivalente, $\mathrm{T}_{\mathrm{e}}$, deverá ser determinada pela Equação 2, em função do volume líquido do bloco.

Construções totalmente grauteadas: a espessura equivalente, $\mathrm{T}_{\mathrm{e}}$, deverá ser a própria espessura do bloco.

Blocos vazados preenchidos com material solto: a espessura equivalente, $\mathrm{T}_{\mathrm{e}}$, deverá ser a própria espessura do bloco quando o material de preenchimento for areia, cascalho, brita, escória, pedra-pomes, xisto expandido, argila expandida, ardósia expandida, cinzas volantes expandidas, cinzas, perlita ou vermiculita.

\section{Determinação da espessura equivalente do acabamento das paredes ( $\left.T_{\text {ef }}\right)$}

O tipo de material e espessura empregados no acabamento das paredes de alvenaria contribuem para aumentar a resistência ao fogo desses elementos.
No caso de acabamento aplicado na face não exposta ao fogo da parede, sua espessura deve ser ajustada por um fator (Tabela 7), que leva em conta tanto os materiais empregados na fabricação do bloco (parede), quanto o material do próprio acabamento. Essa espessura ajustada para o acabamento $\left(\mathrm{T}_{\mathrm{ef}}\right)$ deve ser somada a espessura equivalente do bloco de concreto $\left(\mathrm{T}_{\mathrm{e}}\right)$ para a obtenção da espessura equivalente da parede $\left(\mathrm{T}_{\mathrm{ea}}\right)$, que será empregada para a obtenção da resistência ao fogo, de acordo com a Tabela 3, para paredes de alvenaria de blocos de concreto, ou de acordo com a Tabela 6, para paredes de alvenaria de blocos cerâmicos.

Paredes de alvenaria de concreto ou cerâmica, com acabamentos aplicados na face exposta ao fogo, terão seu tempo de resistência ao fogo incrementado pelo tempo, calculado isoladamente, de resistência ao fogo atribuído ao acabamento (Tabela 8).

Paredes com acabamentos diferentes em suas faces de provável exposição ao fogo devem ser duplamente verificadas, com cada uma de suas faces adotada como sendo a face de exposição ao fogo. A resistência ao fogo dessa parede deve ser tomada como o menor dos tempos obtidos nos cálculos isolados.

Quando os acabamentos (no caso de aplicação em ambas a faces) contribuem para a resistência ao fogo do conjunto, deve-se limitar essa contribuição total (ambos os acabamentos) à metade da contribuição atribuída à parede sem acabamento.

Tabela 7 - Fator multiplicador da espessura de acabamentos aplicados no lado não exposto ao fogo

\begin{tabular}{c|c|c|c|c}
\hline \multirow{2}{*}{$\begin{array}{c}\text { Tipo de material usado na laje ou } \\
\text { parede }\end{array}$} & \multicolumn{3}{|c}{ Tipo de acabamento aplicado à laje ou parede } \\
\cline { 2 - 5 } & $\begin{array}{c}\text { Reboco de cimento } \\
\text { Portland e areia* } \\
\text { ou ladrilho } \\
\text { hidráulico }\end{array}$ & $\begin{array}{c}\text { Reboco de } \\
\text { gesso e } \\
\text { areia }\end{array}$ & $\begin{array}{c}\text { Reboco de gesso } \\
\text { com vermiculita } \\
\text { ou perlita }\end{array}$ & $\begin{array}{c}\text { Drywall } \\
\text { (Gesso } \\
\text { acartonado) }\end{array}$ \\
\hline \multicolumn{3}{|c|}{ Parede de alvenaria de concreto } & \multirow{2}{*}{3,00} \\
\hline $\begin{array}{c}\text { Alvenaria de concreto - Silicioso, } \\
\text { calcário, cal, cinzas, escória de alto } \\
\text { forno resfriada a ar }\end{array}$ & 1,00 & 1,25 & 1,75 & \multirow{2}{*}{2,25} \\
\hline $\begin{array}{c}\text { Alvenaria de concreto - feito com } \\
80 \% \text { ou mais de xisto expandido, } \\
\text { ardósia expandida, argila expandida, } \\
\text { escória expandida ou pedra-pomes. }\end{array}$ & 0,75 & 1,00 & 1,25 & 3,00 \\
\hline $\begin{array}{c}\text { Alvenaria de barro - tijolo maciço de } \\
\text { argila ou xisto }\end{array}$ & 1,00 & 1,25 & 1,75 & 2,25 \\
\hline $\begin{array}{c}\text { Alvenaria de barro - bloco vazado } \\
\text { ou telha de argila ou xisto }\end{array}$ & 0,75 & 1,00 & 1,50 & \\
\hline
\end{tabular}

Nota: *para argamassa de cimento Portland e areia com espessura de 1,6cm ou inferior, aplicada diretamente na parede, em seu lado não exposto ao fogo, o fator multiplicador deverá ser 1.0.

Fonte: ACI/TMS 216.1-14 (ASSOCIATION..., 2014, p. 27). 
Tabela 8 - Tempo atribuído aos materiais de acabamento na face exposta ao fogo de paredes de blocos de concreto ou cerâmica

\begin{tabular}{|c|c|}
\hline Acabamento & Tempo (min) \\
\hline \multicolumn{2}{|l|}{ Drywall (gesso acartonado) } \\
\hline $3 / 8$ pol. $(9,5 \mathrm{~mm})$ & 10 \\
\hline $1 / 2$ pol. $(12,7 \mathrm{~mm})$ & 15 \\
\hline $5 / 8$ pol. $(15,9 \mathrm{~mm})$ & 20 \\
\hline Duas camadas de $3 / 8$ pol. (Duas camadas de $9,5 \mathrm{~mm}$ ) & 25 \\
\hline $\begin{array}{l}\text { Uma camada de } 3 / 8 \text { pol. }(9,5 \mathrm{~mm}) \text { e uma camada de } 1 / 2 \text { pol. }(12,7 \\
\mathrm{mm})\end{array}$ & 35 \\
\hline Duas camadas de $1 / 2$ pol. (Duas camadas de $12,7 \mathrm{~mm}$ ) & 40 \\
\hline \multicolumn{2}{|l|}{ Drywall tipo "X" (resistente ao fogo) } \\
\hline $1 / 2$ pol. $(12,7 \mathrm{~mm})$ & 25 \\
\hline 5/8 pol. $(15,9 \mathrm{~mm})$ & 40 \\
\hline \multicolumn{2}{|c|}{$\begin{array}{c}\text { Argamassa de cimento Portland e areia aplicada diretamente sobre o concreto ou } \\
\text { alvenaria* }\end{array}$} \\
\hline \multicolumn{2}{|c|}{ Argamassa de cimento Portland e areia sobre tela de metal } \\
\hline 3/4 pol. $(19 \mathrm{~mm})$ & 20 \\
\hline $7 / 8$ pol. $(22,2 \mathrm{~mm})$ & 25 \\
\hline 1 pol. $(25,4 \mathrm{~mm})$ & 30 \\
\hline \multicolumn{2}{|l|}{ Argamassa de gesso e areia sobre ripas de gesso de $3 / 8$ pol. } \\
\hline $1 / 2$ pol. $(12,7 \mathrm{~mm})$ & 35 \\
\hline $5 / 8$ pol. $(15,9 \mathrm{~mm})$ & 40 \\
\hline 3/4 pol. $(19 \mathrm{~mm})$ & 50 \\
\hline \multicolumn{2}{|l|}{ Argamassa de gesso e areia sobre tela de metal } \\
\hline $3 / 4$ pol. $(19 \mathrm{~mm})$ & 50 \\
\hline $7 / 8$ pol. $(22,2 \mathrm{~mm})$ & 60 \\
\hline 1 pol. $(25,4 \mathrm{~mm})$ & 80 \\
\hline
\end{tabular}

Nota: *para fins de determinação da contribuição da argamassa de cimento Portland e areia para a espessura equivalente do concreto ou alvenaria para usos nas tabelas 3 e 4 ( 3.1 e 4.1 do código), será permitido o uso da espessura real da argamassa ou 5/8 pol., o menor entre os dois.

Fonte: ACI/TMS 216.1-14 (ASSOCIATION..., 2014, p. 28, tradução nossa) (valores em mm acrescentados).

\section{Paredes múltiplas de alvenaria de blocos de concreto e/ou cerâmica}

A resistência ao fogo de uma única parede de alvenaria deve ser determinada de acordo com a Tabela 3, para o caso de paredes de blocos de concreto, e de acordo com a Tabela 6, para o caso de paredes de blocos cerâmicos. No caso de paredes múltiplas (Figura 4), a resistência ao fogo deve ser calculada considerando-se a resistência ao fogo de cada parede do conjunto e também a influência de eventual espaço entre elas, de acordo com a Equação 3, válida para combinações de paredes de alvenaria de concreto, alvenaria cerâmica, ou uma combinação desses dois materiais.

$R=\left(R_{1}^{0,59}+R_{2}^{0,59}+\cdots+R_{n}^{0,59}+A_{1}+A_{2}+\cdots+\right.$ $\left.A_{n}\right)^{1,7} \quad$ Eq. 3

Onde:
$\mathrm{R}_{1}, \mathrm{R}_{2}, \ldots, \mathrm{R}_{\mathrm{n}}$ representam a resistência ao fogo das camadas $1,2, \ldots, \mathrm{n}$, respectivamente, em horas; e

$\mathrm{A}_{1}=\mathrm{A}_{2}=\mathrm{A}_{\mathrm{n}}=0,30$, um fator que leva em consideração o espaço entre as paredes (preenchido com ar), com valores entre $1,27 \mathrm{~cm} \mathrm{e}$ $8,89 \mathrm{~cm}$.

Para os valores de $\mathrm{R}_{1}, \mathrm{R}_{2}, \ldots, \mathrm{R}_{\mathrm{n}}$, usar a Tabela 6 para alvenaria cerâmica, ou a Tabela 3 para alvenaria de concreto.

É importante ressaltar que, caso o espaço entre as paredes seja maior que $8,89 \mathrm{~cm}$, nem o espaço de ar, nem a parede que se encontra mais externamente a ele (em relação ao incêndio), e nem as paredes na sequência poderão ser consideradas como elementos resistentes ao incêndio. Caso o espaço seja menor que $1,27 \mathrm{~cm}$, as duas (ou mais) paredes deverão ser consideradas como uma só, sem considerar o ar entre elas como um elemento resistente. 
Figura 4 - Paredes múltiplas

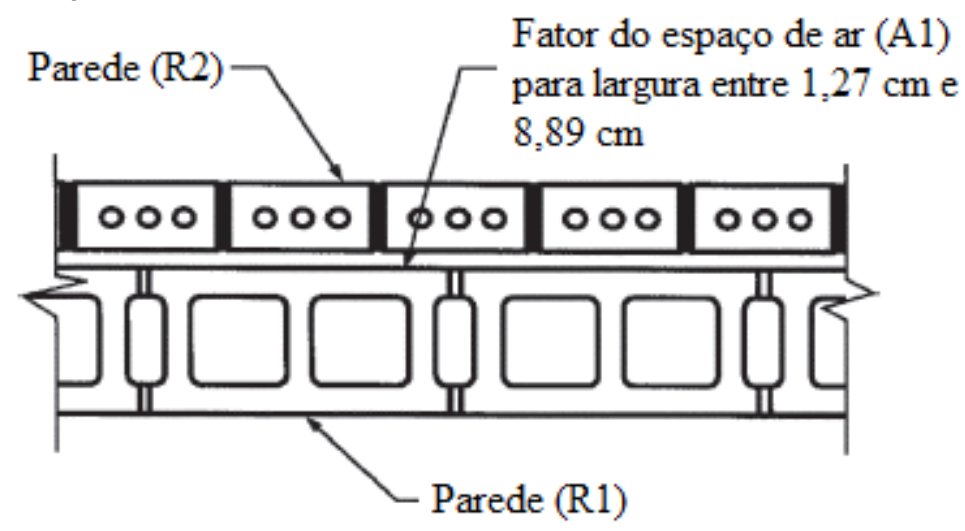

$$
\begin{aligned}
& \mathrm{R} 1=\text { tempo de resistência ao fogo da parede } 1 \\
& \mathrm{R} 2=\text { tempo de resistência ao fogo da parede } 2 \\
& \mathrm{~A} 1=\text { fator do espaço de } \mathrm{ar}=0.3
\end{aligned}
$$

Fonte: ACI/TMS216.1-14 (ASSOCIATION..., 2014, p. 22, tradução nossa).

\section{Código europeu: eurocode 6 - en 1996-1.2 (EUROPEAN..., 2005)}

O código europeu especifica as exigências necessárias a serem cumpridas no dimensionamento de estruturas em alvenaria em situação de incêndio.

Para determinação do tempo de resistência ao fogo deve-se conhecer o tipo de bloco empregado, os materiais componentes dos blocos e o tipo de revestimento a ser aplicado.

Assim como em outras normas descritas, para a exposição ao fogo as estruturas devem cumprir os critérios de resistência mecânica (R), de estanqueidade (E) e de isolamento térmico (I). Observa-se a adição de um novo critério, o impacto mecânico (M). Tais critérios, com base nas funções previstas para a parede de alvenaria na edificação, podem ser agrupados na classificação a seguir:

(a) paredes com função resistente unicamente: critério R;

(b) paredes com função de isolamento térmico e estanqueidade: critérios EI;

(c) paredes com função resistente, de isolamento térmico e de estanqueidade: critério REI;

(d) paredes com função resistente, de isolamento térmico, de estanqueidade e de resistência a impactos mecânicos: critérios REI-M; e

(e) paredes com função de isolamento térmico, de estanqueidade e de resistência a impactos mecânicos: critérios EI-M.
A avaliação das paredes de alvenaria estrutural em situação de incêndio pode ser feita através de ensaios em laboratório, por métodos de dimensionamento analíticos simplificados, por tabelas ou por modelos numéricos feitos em softwares como Abaqus, Ansys, etc.

\section{Avaliação por método tabular}

As tabelas estão contidas no Anexo B do código e fornecem a espessura mínima necessária da parede de alvenaria para o tempo de resistência ao fogo requerido.

As tabelas são divididas, inicialmente, pela função da parede na edificação (critérios de resistência ao fogo) e pelo tipo de material do bloco da parede (cerâmica, concreto com agregado leve ou agregado denso, concreto celular, etc.). A seguir, cada tabela é dividida em função da resistência à compressão dos blocos $\left(\mathrm{f}_{\mathrm{b}}\right)$, em função da densidade dos blocos $(\rho)$ e, por fim, em função da relação entre as solicitações de cálculo da parede em situação de incêndio e as solicitações de cálculo em situação normal $(\alpha)$.

Para ilustrar, abaixo estão algumas tabelas do código europeu, representadas pelas Tabelas 9 e 10 .

As espessuras mínimas são indicadas nessas tabelas em valores únicos ou em intervalos recomendados. O intervalo recomendado é expresso por espessuras separadas por uma barra. Como exemplo, a indicação "90/100", na tabela, representa a recomendação de que a espessura mínima a se adotar para a parede deve estar entre $90 \mathrm{~mm}$ e $100 \mathrm{~mm}$.

98 Leite, H. A. L.; Moreno Júnior, A. L.; Torres, D. L. 
Tabela 9 - Espessura mínima de paredes carregadas (critério REI) para concreto denso e leve

\begin{tabular}{|c|c|c|c|c|c|c|c|c|}
\hline \multirow[b]{2}{*}{$\begin{array}{l}N^{0} \text { da } \\
\text { linha }\end{array}$} & \multirow{2}{*}{$\begin{array}{l}\text { Propriedades } \\
\text { dos materiais } \\
\text { Resistência à } \\
\text { compressão }\left(\mathbf{f}_{\mathrm{b}}\right) \\
{\left[\mathrm{N} / \mathrm{mm}^{2}\right]} \\
\text { Densidade }(\rho) \\
{\left[\mathrm{kg} / \mathrm{m}^{3}\right]}\end{array}$} & \multicolumn{7}{|c|}{$\begin{array}{c}\text { Mínima espessura }(\mathrm{mm}) \mathbf{t}_{\mathrm{f}} \text { para o tempo (minutos) de resistência ao fogo para a } \\
\text { classificação REI }\end{array}$} \\
\hline & & 30 & 45 & 60 & 90 & 120 & 180 & 240 \\
\hline 1 & \multicolumn{8}{|c|}{$\begin{array}{l}\text { Blocos do Grupo } 1 \\
\text { Argamassa: uso geral, camada fina, leve }\end{array}$} \\
\hline 1.1 & \multicolumn{8}{|l|}{$\begin{array}{l}\text { Agregado leve } \\
2 \leq \mathrm{f}_{\mathrm{b}} \leq 15 \\
400 \leq \rho \leq 1600\end{array}$} \\
\hline $\begin{array}{l}1.1 .1 \\
1.1 .2\end{array}$ & $\alpha \leq 1,0$ & $\begin{array}{c}90 / 170 \\
(90 / 140)\end{array}$ & $\begin{array}{c}90 / 170 \\
(90 / 140)\end{array}$ & $\begin{array}{c}90 / 170 \\
(90 / 140)\end{array}$ & $\begin{array}{l}100 / 170 \\
(90 / 140)\end{array}$ & $\begin{array}{l}100 / 190 \\
(90 / 170)\end{array}$ & $\begin{array}{c}140 / 240 \\
(100 / 190)\end{array}$ & $\begin{array}{r}150 / 300 \\
(100 / 240)\end{array}$ \\
\hline $\begin{array}{l}1.1 .3 \\
1.1 .4\end{array}$ & $\alpha \leq 0,6$ & $\begin{array}{c}70 / 140 \\
(60 / 100)\end{array}$ & $\begin{array}{c}70 / 140 \\
(60 / 100)\end{array}$ & $\begin{array}{c}70 / 140 \\
(60 / 100)\end{array}$ & $\begin{array}{c}90 / 170 \\
(70 / 100)\end{array}$ & $\begin{array}{c}90 / 170 \\
(70 / 140)\end{array}$ & $\begin{array}{l}100 / 190 \\
(90 / 170)\end{array}$ & $\begin{array}{l}100 / 240 \\
(90 / 190)\end{array}$ \\
\hline 1.2 & \multicolumn{8}{|l|}{$\begin{array}{l}\text { Agregado denso } \\
6 \leq \mathrm{f}_{\mathrm{b}} \leq 35 \\
1200 \leq \rho \leq 2400\end{array}$} \\
\hline $\begin{array}{l}1.2 .1 \\
1.2 .2\end{array}$ & $\alpha \leq 1,0$ & $\begin{array}{c}90 / 170 \\
(90 / 140)\end{array}$ & $\begin{array}{c}90 / 170 \\
(100 / 140)\end{array}$ & $\begin{array}{c}90 / 170 \\
(90 / 140)\end{array}$ & $\begin{array}{c}90 / 170 \\
(90 / 140)\end{array}$ & $\begin{array}{l}100 / 190 \\
(90 / 170) \\
\end{array}$ & $\begin{array}{c}140 / 240 \\
(100 / 190) \\
\end{array}$ & $\begin{array}{c}150 / 300 \\
(100 / 240) \\
\end{array}$ \\
\hline $\begin{array}{l}1.2 .3 \\
1.2 .4\end{array}$ & $\alpha \leq 0,6$ & $\begin{array}{c}70 / 140 \\
(60 / 100)\end{array}$ & $\begin{array}{c}90 / 140 \\
(70 / 100)\end{array}$ & $\begin{array}{c}70 / 140 \\
(70 / 100)\end{array}$ & $\begin{array}{c}90 / 170 \\
(70 / 100)\end{array}$ & $\begin{array}{c}90 / 170 \\
(70 / 140)\end{array}$ & $\begin{array}{l}100 / 190 \\
(90 / 170)\end{array}$ & $\begin{array}{c}140 / 240 \\
(100 / 190)\end{array}$ \\
\hline
\end{tabular}

Fonte: European Committee For Standardization (2005, p. 50, tradução nossa).

Tabela 10 - Espessura mínima de paredes carregadas (critério REI) para alvenaria cerâmica

\begin{tabular}{|c|c|c|c|c|c|c|c|c|}
\hline \multirow{2}{*}{$\begin{array}{l}N^{0} \text { da } \\
\text { linha }\end{array}$} & \multirow{2}{*}{$\begin{array}{l}\text { Propriedades dos } \\
\text { materiais } \\
\text { Resistência à } \\
\text { compressão }\left(\mathbf{f}_{\mathbf{b}}\right) \\
{\left[\mathrm{N} / \mathbf{m m}^{2}\right]} \\
\text { Densidade }(\rho)\left[\mathrm{kg} / \mathrm{m}^{3}\right]\end{array}$} & \multicolumn{7}{|c|}{$\begin{array}{c}\text { Mínima espessura }(\mathrm{mm}) \mathbf{t}_{\mathrm{f}} \text { para o tempo (minutos) de resistência ao fogo para a } \\
\text { classificação REI }\end{array}$} \\
\hline & & 30 & 45 & 60 & 90 & 120 & 180 & 240 \\
\hline $1 \mathrm{~S}$ & \multirow{2}{*}{\multicolumn{8}{|c|}{$\begin{array}{l}\text { Blocos do Grupo } 1 \mathrm{~S} \\
5 \leq \mathrm{f}_{\mathrm{b}} \leq 75 \text { argamassa de uso geral } \\
5 \leq \mathrm{f}_{\mathrm{b}} \leq 50 \text { camada fina de argamassa } \\
1000 \leq \rho \leq 14400\end{array}$}} \\
\hline 1S.1 & & & & & & & & \\
\hline $\begin{array}{l}1 \mathrm{~S} .1 .1 \\
1 \mathrm{~S} .1 .2\end{array}$ & $\alpha \leq 1,0$ & $\begin{array}{c}90 \\
(70 / 90)\end{array}$ & $\begin{array}{c}90 \\
(70 / 90)\end{array}$ & $\begin{array}{c}90 \\
(70 / 90)\end{array}$ & $\begin{array}{c}100 \\
(70 / 90)\end{array}$ & $\begin{array}{l}100 / 140 \\
(90 / 140)\end{array}$ & $\begin{array}{c}170 / 190 \\
(110 / 140)\end{array}$ & $\begin{array}{c}170 / 190 \\
(170 / 190)\end{array}$ \\
\hline $\begin{array}{l}1 \mathrm{~S} .1 .3 \\
1 \mathrm{~S} .1 .4\end{array}$ & $\alpha \leq 0,6$ & $\begin{array}{c}90 \\
(70 / 90)\end{array}$ & $\begin{array}{c}90 \\
(70 / 90)\end{array}$ & $\begin{array}{c}90 \\
(70 / 90)\end{array}$ & $\begin{array}{c}100 \\
(70 / 90)\end{array}$ & $\begin{array}{c}100 / 140 \\
(100 / 140)\end{array}$ & $\begin{array}{c}170 \\
(110 / 140)\end{array}$ & $\begin{array}{c}170 \\
(140 / 170) \\
\end{array}$ \\
\hline 1 & \multicolumn{8}{|c|}{$\begin{array}{l}\text { Blocos do Grupo } 1 \\
\text { Argamassa: uso geral, camada fina, leve }\end{array}$} \\
\hline 1.2 & \multicolumn{8}{|c|}{$\begin{array}{l}5 \leq \mathrm{f}_{\mathrm{b}} \leq 75 \\
800 \leq \rho \leq 2400\end{array}$} \\
\hline $\begin{array}{l}1.2 .1 \\
1.2 .2\end{array}$ & $\alpha \leq 1,0$ & $\begin{array}{l}90 / 100 \\
(70 / 90)\end{array}$ & $\begin{array}{l}90 / 100 \\
(70 / 90)\end{array}$ & $\begin{array}{l}90 / 100 \\
(70 / 90)\end{array}$ & $\begin{array}{l}100 / 170 \\
(70 / 90)\end{array}$ & $\begin{array}{c}140 / 170 \\
(100 / 140)\end{array}$ & $\begin{array}{c}170 / 190 \\
(110 / 170)\end{array}$ & $\begin{array}{c}190 / 210 \\
(170 / 190)\end{array}$ \\
\hline $\begin{array}{l}1.2 .3 \\
1.2 .4\end{array}$ & $\alpha \leq 0,6$ & $\begin{array}{l}90 / 100 \\
(70 / 90)\end{array}$ & $\begin{array}{l}90 / 100 \\
(70 / 90)\end{array}$ & $\begin{array}{l}90 / 100 \\
(70 / 90)\end{array}$ & $\begin{array}{l}100 / 140 \\
(70 / 90)\end{array}$ & $\begin{array}{c}140 / 170 \\
(100 / 140)\end{array}$ & $\begin{array}{c}140 / 170 \\
(110 / 170)\end{array}$ & $\begin{array}{c}190 / 200 \\
(170 / 190)\end{array}$ \\
\hline
\end{tabular}

Fonte: European Committee For Standardization (2005, p. 32, tradução nossa).

Da mesma forma, as espessuras mínimas (ou intervalos) são expressas, na tabela, com a opção de se empregar, ou não, acabamentos adequados às exigências do código. Valores entre parênteses representam as espessuras mínimas (ou intervalos de espessuras) recomendadas para paredes com acabamentos adequados às exigências do código (acabamentos com espessura mínima de $10 \mathrm{~mm}$ nas duas faces de uma parede simples, ou na face exposta ao fogo em uma parede dupla). 


\section{Avaliação por métodos de dimensionamento analíticos simplificados}

O código em questão restringe o dimensionamento de paredes de alvenaria estrutural em situação de incêndio pelo método simplificado às paredes executadas com blocos e argamassas específicos (Tabela 11).

O método simplificado, basicamente, consiste na determinação de duas isotermas da seção, uma para temperatura $\theta_{1}$ (temperatura até a qual se pode considerar resistência à compressão residual da alvenaria) e outra para temperatura $\theta_{2}$ (temperatura acima da qual se pode considerar como nula a resistência à compressão da alvenaria). A partir do traçado dessas isotermas na seção transversal, a parede é avaliada, em situação de incêndio, com a seção reduzida (toda a área da seção com temperatura acima de $\theta_{2}$ descartada) e com parte da seção já reduzida com resistência à compressão menor do que aquela obtida em situação ambiente (região da seção transversal com temperaturas entre $\theta_{1}$ e $\theta_{2}$ ). A Figura 5 exemplifica esse procedimento para o caso de um pilar em alvenaria estrutural.

A verificação da seção é feita no Estado Limite Último e as ações são combinadas de acordo com as recomendações usuais do código (similar ao que ocorre com procedimentos já consagrados para o concreto ou para o aço).

No Estado Limite Último, para a situação de incêndio, o valor da força vertical solicitante de cálculo em uma parede ou pilar deve ser menor ou igual ao valor da força vertical resistente de cálculo da parede ou pilar (Eq. 4).

$N_{S d} \leq N_{R d, f i \theta 2}$

$\mathrm{O}$ valor da força vertical resistente de cálculo de uma parede ou pilar é dada por (Eq. 5):

$N_{R d, f i \theta 2}=\Phi\left(f_{d \theta 1} A_{\theta 1}+f_{d \theta 2} A_{\theta 2}\right)$

Onde:

$\mathrm{A}=$ área total de alvenaria

$\mathrm{A}_{\theta 1}=$ área de alvenaria até $\theta_{1}$

$\mathrm{A}_{\theta 2}=$ área de alvenaria entre $\theta_{1}$ e $\theta_{2}$

$\theta_{1}=$ temperatura até a qual pode-se utilizar a capacidade resistente da alvenaria

$\theta_{2}=$ temperatura acima da qual o material é desprezado

$\mathrm{N}_{\mathrm{Sd}}=$ valor da força vertical solicitante de cálculo

$\mathrm{N}_{\mathrm{Rd}, \text { fï2 }}=$ valor da força vertical resistente de cálculo, em situação de incêndio

$\mathrm{f}_{\mathrm{d} \theta 1}=$ resistência à compressão, de cálculo, da alvenaria até $\theta_{1}$

$\mathrm{f}_{\mathrm{d} \theta 2}=$ resistência à compressão, de cálculo, da alvenaria entre $\theta_{1}$ e $\theta_{2}$

$\mathrm{e}_{\Delta \theta}=$ excentricidade devido à variação de temperatura na alvenaria

$\Phi=$ fator de minoração da capacidade portante da parede que leva em consideração eventual excentricidade adicional $\mathrm{e}_{\Delta \theta}$

Figura 5 - Ilustração de áreas da alvenaria a temperaturas até $\theta_{1}$, entre $\theta_{1}$ e $\theta_{2}$ e áreas estruturalmente ineficientes (acima de $\theta_{2}$ )

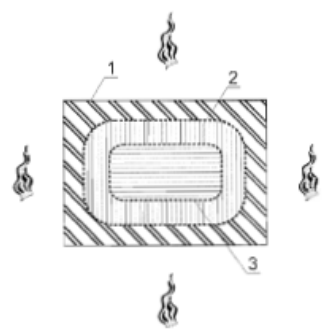
(a) seção transversal de um pilar exposto
ao fogo com curvas isotérmicas reais

(b) seção transversal de um pilar exposto ao fogo com curvas isotérmicas ajustadas para o método
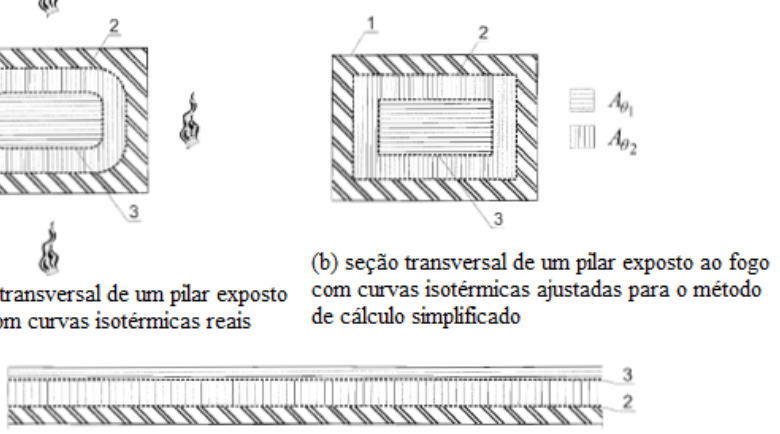

(3)

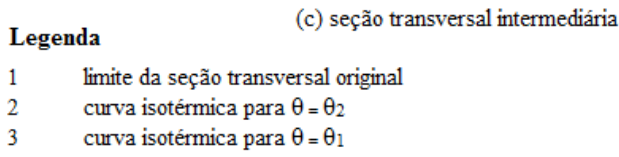

Fonte: European Committee For Standardization (2005, p. 66, tradução nossa). 
Tabela 11 - Valores das temperaturas $\theta_{1}$ e $\theta_{2}$ em função dos materiais de execução da parede de alvenaria

\begin{tabular}{c|c|c}
\hline Blocos de alvenaria e argamassa (superfície & \multicolumn{2}{|c}{ Temperatura $\left({ }^{\circ} \mathrm{C}\right)$} \\
\cline { 2 - 3 } desprotegida) & $\theta_{2}$ & $\theta_{1}$ \\
\hline Blocos cerâmicos com argamassa comum & 600 & 100 \\
\hline $\begin{array}{c}\text { Blocos de silicato de cálcio com uma fina } \\
\text { camada de argamassa }\end{array}$ & 500 & 100 \\
\hline $\begin{array}{c}\text { Bloco de agregado leve (pedra-pomes) com } \\
\text { argamassa comum }\end{array}$ & 400 & 100 \\
\hline $\begin{array}{c}\text { Bloco de agregado denso com argamassa comum } \\
\text { Bloco celular auto clavado com uma fina } \\
\text { camada de argamassa }\end{array}$ & 500 & 200 \\
\hline
\end{tabular}

Fonte: European Committee For Standardization (2005, p. 67, tradução nossa).

A excentricidade, $\mathrm{e}_{\Delta \theta}$, devido a variação de temperatura na parede ou pilar de alvenaria, para uso no método simplificado de cálculo pode ser obtida a partir da Equação 6:

$\mathrm{e}_{\Delta \theta}=\frac{1}{8} h_{e f}^{2} \frac{\alpha_{t}\left(\theta_{2}-20\right)}{t_{F r}} \leq h_{e f} / 20$

Eq. 6

Onde:

$\mathrm{e}_{\Delta \theta}=0$, quando se considera todas as faces do elemento sob ação do fogo;

$\theta_{2}=$ temperatura acima da qual despreza-se a resistência à compressão do material, em ${ }^{\circ} \mathrm{C}$;

$\mathrm{h}_{\mathrm{ef}}=$ altura efetiva da parede;

$\alpha_{\mathrm{t}}=$ coeficiente de expansão térmica; e

$\mathrm{t}_{\mathrm{Fr}}=$ espessura da seção transversal cuja temperatura não exceda $\theta_{2}$.

Por fim, observa-se que a distribuição de temperaturas (isotermas) na seção transversal da parede ou pilar de alvenaria, ao longo do tempo de exposição ao fogo do elemento, deve ser obtida através de ensaio do elemento em laboratório ou a partir de uma base de dados (tabelas de isotermas) confiável.

\section{Código australiano: AS 3700 (AUSTRALIAN..., 2011)}

O código australiano é o único código, dentre os abordados, que leva em conta, explicitamente, todos os três critérios para o dimensionamento de estruturas de alvenaria em situação de incêndio (resistência mecânica, isolamento térmico e estanqueidade).

São especificados níveis de resistência ao fogo (Fire Resistance Levels - FRLs) para as paredes, em função de critérios ligados à adequabilidade estrutural (estabilidade contra o colapso), integridade/estanqueidade (capacidade resistente à fissuração excessiva e passagem de gases e chamas) e isolamento térmico (capacidade resistente à passagem de calor).

Os fatores que afetam a integridade/estanqueidade da parede incluem a espessura dos blocos de alvenaria e os materiais utilizados em sua fabricação.

O isolamento térmico da parede é afetado pela densidade e composição dos blocos, pela espessura dos blocos, por quaisquer acabamentos ou revestimentos aplicados sobre a parede e pela existência, ou não, de grauteamento.

A adequabilidade estrutural de uma parede é afetada pela expansão térmica do material utilizado na fabricação dos blocos de alvenaria, das vinculações das paredes em suas extremidades e de sua esbeltez (verificada de acordo com seu índice, $\mathrm{S}_{\mathrm{rf}}-$ slenderness ratio on fire resistance), que, por sua vez, depende da espessura da parede e do distanciamento entre seus apoios verticais e horizontais.

A norma australiana dá duas opções ao projetista de paredes de alvenaria sujeitas a incêndios: projetar a estrutura para os critérios de adequabilidade estrutural, integridade e isolamento térmico, respeitando os limites tabelados de espessura e esbeltez da parede e cobrimento de armadura; ou projetar a estrutura com base em resultados de ensaio em laboratório, com ábacos de dimensionamento fornecidos pelos fabricantes de blocos daquele país.

\section{Dimensionamento de acordo com o método tabelado}

Esta especificação foi feita pela norma australiana, AS 3700 (AUSTRALIAN..., 2011) e, segundo o Manual M55 (CONCRETE..., 2012), é bastante conservadora. Os limites das tabelas são representativos para qualquer tipo de alvenaria fabricada na Austrália, incluindo as que 
apresentam má adequabilidade estrutural e baixo isolamento térmico.

Para se dimensionar uma parede de acordo com o critério (FRL) de adequabilidade estrutural, utilizando os valores tabelados, seu índice de esbeltez não deverá exceder o valor de referência da Tabela 12. Se a esbeltez da parede é maior que a máxima permitida, a parede deverá ser recalculada com uma espessura maior. Pode-se também modificar o arranjo estrutural de forma a aumentar a rigidez do elemento, introduzindo novas restrições (travamentos) na parede.

O índice de esbeltez é definido pelas Equações de 7 a 9, função do tipo de vinculação da parede.

Paredes que não possuem apoio nas laterais têm o índice de esbeltez definido pela Equação 7.

$S_{r f}=\frac{a_{v f \cdot H}}{t}$

Eq. 7

Paredes que possuem apoios em apenas uma ou nas duas laterais têm seu índice de esbeltez calculado pelo menor valor dado nas Equações 7 a 9.

$S_{r f}=\frac{0,7}{t} \sqrt{a_{v f} \cdot H \cdot a_{k} \cdot L}$

Eq. 8

$S_{r f}=a_{k} \frac{L}{t}$

Eq. 9
Onde:

$\mathrm{S}_{\mathrm{rf}}=$ índice de esbeltez da parede em situação de incêndio;

$a_{\mathrm{vf}}=$ igual a 0,75 se o elemento possui apoios em toda sua extensão lateral. Caso não existia tal restrição, o valor a ser adotado é 2,0;

$\mathrm{H}=$ altura do membro entre os travamentos verticais da parede;

$\mathrm{t}=$ espessura total da parede. Para paredes duplas ou com cavidades, a espessura da parede deverá atender ao disposto em 6.1.1;

$\mathrm{a}_{\mathrm{k}}=$ no caso da parede possuir apoios superior $\mathrm{e}$ inferior, o coeficiente vale 1,0 . No caso da parede possuir somente apoio inferior, o coeficiente vale 2,5; e

$\mathrm{L}=$ comprimento da parede entre as faces laterais restringidas ou o comprimento de uma parede com travamento lateral em apenas uma de suas extremidades. No caso de juntas prumo ou no caso de paredes com aberturas, o comprimento é medido até a junta ou abertura.

Existem também valores tabelados para a verificação do isolamento térmico, de acordo com o exposto na Tabela 13.

Tabela 12 - Índice de esbeltez máximo para adequabilidade estrutural

\begin{tabular}{l|c|c|c|c|c|c}
\hline Tipo de bloco & \multicolumn{7}{l}{ Tempo de resistência ao fogo (min) } \\
\cline { 2 - 6 } & $\mathbf{3 0}$ & $\mathbf{6 0}$ & $\mathbf{9 0}$ & $\mathbf{1 2 0}$ & $\mathbf{1 8 0}$ & $\mathbf{2 4 0}$ \\
\hline 1 Alvenaria não armada & 25,0 & 22,5 & 21,0 & 20,0 & 18,0 & 17,0 \\
\hline Blocos de argila & \multicolumn{7}{|c}{} \\
\hline (ii) Blocos de silicato de cálcio com agregado basáltico & 20,5 & 19,0 & 18,0 & 17,5 & 16,5 & 15,5 \\
\hline (A) menos de 45\% de todos os agregados & 25,0 & 22,5 & 21,0 & 20,0 & 18,0 & 17,0 \\
\hline (B) pelo menos 45\% de todos os agregados & 25,0 & \multicolumn{5}{|c}{} \\
\hline (iii) Blocos de concreto com agregados basálticos & 19,5 & 18,0 & 17,0 & 16,0 & 15,5 & 15,0 \\
\hline (A) menos de 45\% de todos os agregados & 25,0 & 22,5 & 21,0 & 20,0 & 18,0 & 17,0 \\
\hline (B) pelo menos 45\% de todos os agregados & 36,0 & 36,0 & 36,0 & 36,0 & 36,0 & 36,0 \\
\hline
\end{tabular}

Fonte: AS 3700 (AUSTRALIAN..., 2011, p. 57, tradução nossa).

Tabela 13 - Espessura mínima de paredes considerando o isolamento térmico

\begin{tabular}{l|l|l|l|l|l|c}
\hline \multirow{2}{*}{ Tipo de bloco } & \multicolumn{6}{|c}{ Tempo de resistência ao fogo (min) } \\
\cline { 2 - 7 } & $\mathbf{3 0}$ & $\mathbf{6 0}$ & $\mathbf{9 0}$ & $\mathbf{1 2 0}$ & $\mathbf{1 8 0}$ & $\mathbf{2 4 0}$ \\
\hline Argila & 60 & 90 & 110 & 130 & 160 & 180 \\
\hline Silicato de cálcio & 50 & 70 & 90 & 110 & 135 & 160 \\
\hline Concreto com densidade: & 55 & 80 & 100 & 120 & 150 & 180 \\
\hline (a) superior a $1800 \mathrm{~kg} / \mathrm{m}^{3}$ & 55 & 75 & 90 & 110 & 135 & 160 \\
\hline (b) igual ou inferior a $1800 \mathrm{~kg} / \mathrm{m}^{3}$ &
\end{tabular}

Fonte: AS 3700 (AUSTRALIAN..., 2011, p. 61, tradução nossa). 


\section{Paredes Duplas ou com Cavidades}

(a) quando as duas paredes possuem carregamento axial, com valores que não diferem $10 \%$ um do outro, incluindo o caso de ambas as paredes não possuírem carregamento algum, o índice de esbeltez deve ser baseado em dois terços da soma das espessuras das duas paredes e das condições de apoio da parede não exposta ao fogo. (Figura 6a); e

(b) para os demais casos, o índice de esbeltez deve ser baseado na espessura e condições de apoio da parede mais carregada (Figura 6b).

Se as duas paredes forem constituídas por blocos de diferentes tipos e seu índice de esbeltez for determinado pelo item (a), o cálculo para adequabilidade estrutural deverá ser baseado no material menos resistente.

\section{Dimensionamento de acordo com dados experimentais}

Uma opção ao dimensionamento anterior é o dimensionamento através de ábacos fornecidos, geralmente, pelos fabricantes de blocos australianos. Os fabricantes de blocos fornecem grupos de ábacos que oferecem a possibilidade de verificação rápida do critério de adequabilidade estrutural. Nesses ábacos, os demais critérios (estanqueidade e isolamento térmico) já estão considerados. Basta, então, ajustar a espessura da parede para que o critério adequabilidade estrutural também seja satisfeito. Tal procedimento é ilustrado pelas Figuras 7 e 8 . A Figura 7 é para alvenaria de blocos de concreto e a 8, para alvenaria de blocos cerâmicos.

Pela Figura 8, pode-se perceber que, uma parede de alvenaria cerâmica, apoiada em todas as extremidades, com seis metros de comprimento e quatro de altura, resiste a um incêndio durante sessenta minutos, quando se considera o critério de adequabilidade estrutural.

Figura 6 - Paredes duplas expostas ao fogo
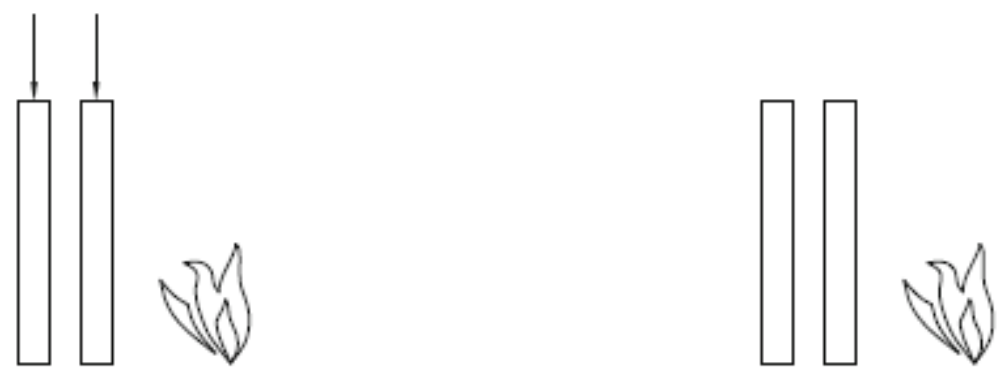

(a) As duas paredes são igualmente carregadas
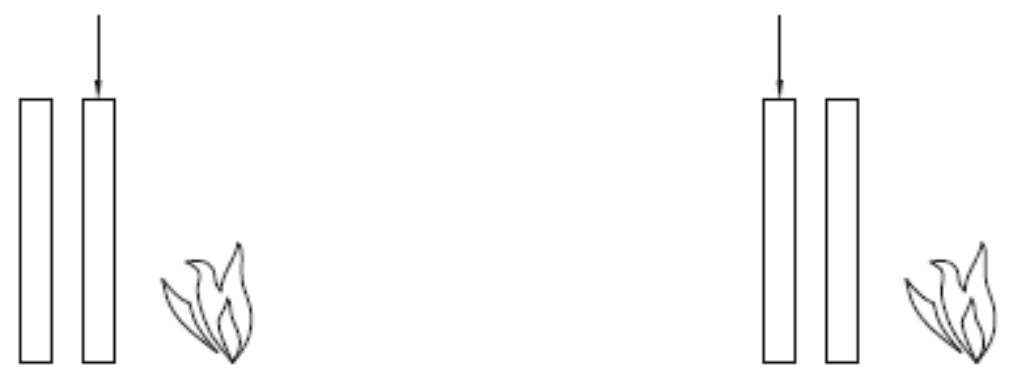

(b) Uma parede é mais carregada que a outra

Fonte: AS 3700 (AUSTRALIAN..., 2011, p. 56, tradução nossa). 
Figura 7 - Adequabilidade estrutural de uma parede de blocos de concreto

\section{Blocos de Escória}

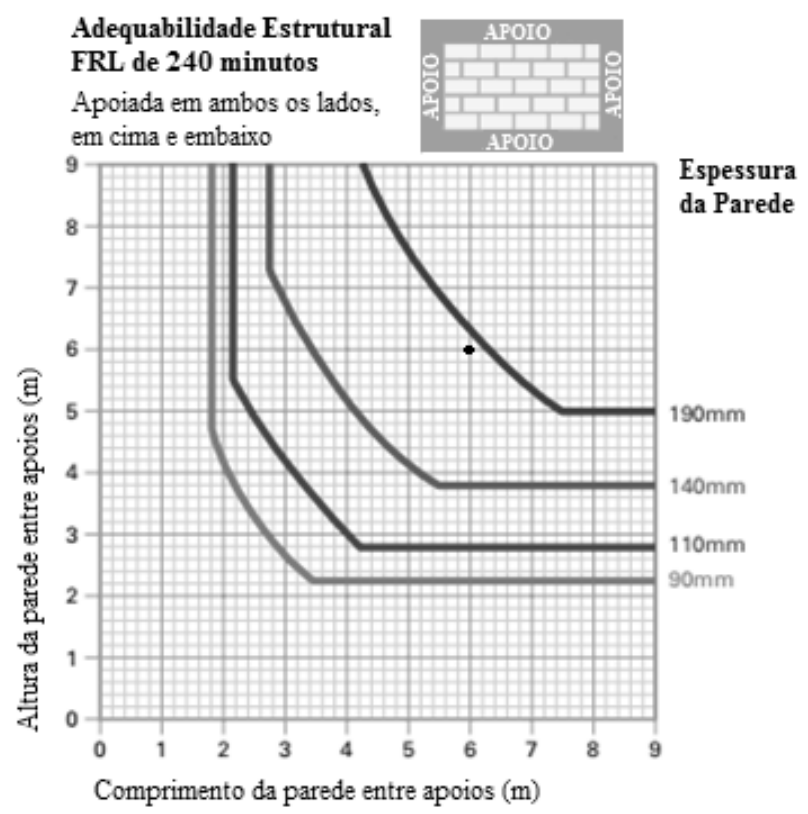

\author{
Exemplo: \\ 1. Selecionar o material apropriado do bloco \\ 2. Selecionar a página apropriada com \\ adequabilidade estrutural para o tempo requerido \\ (240 minutos no exemplo) \\ 3. Selecionar o gráfico apropriado para o critério de \\ restrições (apoios) da parede. (No exemplo, apoio em \\ ambos os lados, em cima e embaixo). \\ 4. Plotar a intersecção da Altura da parede e \\ Comprimento da parede no gráfico (6 $\mathrm{m}$ de altura $\mathrm{x}$ \\ $6 \mathrm{~m}$ de comprimento no exemplo) \\ 5. O resultado DEVE ESTAR ABAIXO da linha \\ colorida indicada para a espessura escolhida para a \\ alvenaria. No exemplo, o resultado está acima da \\ linha para blocos de $140 \mathrm{~mm}$, mas abaixo da linha \\ para blocos de $190 \mathrm{~mm}$. Portanto, blocos de $190 \mathrm{~mm}$ \\ são adequados.
}

Fonte: adaptado de Boral Masonry ano (2009, p. C11).

Figura 8 - Adequabilidade estrutural para uma parede de blocos cerâmicos de $140 \mathrm{~mm}$ de espessura, apoiada em todas as extremidades

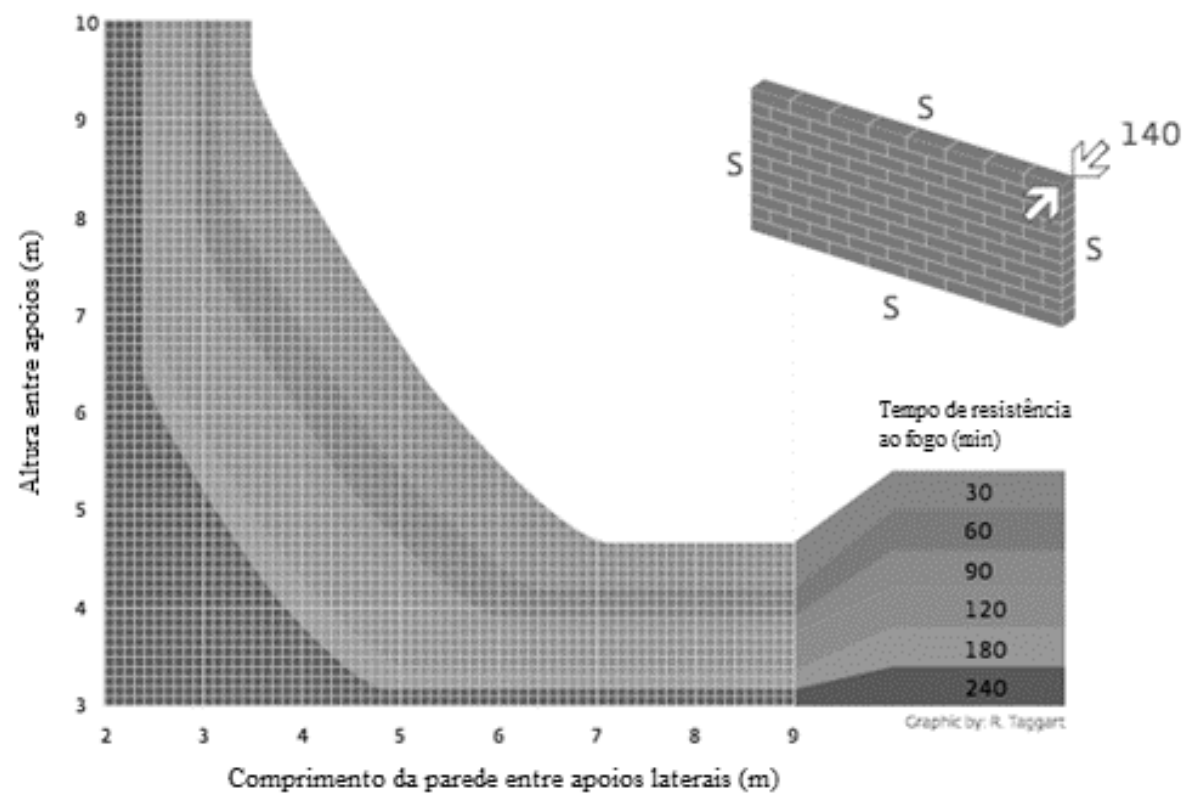

Fonte: Torres (2012, p. 47, tradução nossa).

\section{Considerações finais}

Incêndios muitas vezes são inevitáveis na construção civil, e as estruturas não devem entrar em colapso antes que ocorra sua total evacuação, pois a prioridade maior é poupar vidas. Em segundo plano, deve-se minimizar o dano estrutural. Para isso, existe a normatização de segurança das estruturas em situação de incêndio. No entanto, não há, no país, normatização para alvenaria estrutural nessa situação, e, portanto, a consulta a normas internacionalmente respeitadas sobre o assunto continua sendo necessária. 
Neste trabalho, com intuito de subsidiar futura normatização nacional, foram apresentados os procedimentos de dimensionamento da alvenaria estrutural em situação de incêndio de acordo com a norma americana, a europeia e a australiana.

A norma americana fornece tabelas de espessuras mínimas para que paredes de alvenaria resistam a um incêndio durante um determinado tempo. Tais tabelas estão divididas pelo tipo de agregado utilizado nos blocos. Ela também leva em conta o efeito de diferentes tipos de acabamentos nas paredes, se ele está no lado exposto ao fogo ou no outro lado. É bem completa quando se considera critérios de isolamento térmico ou de estanqueidade, deixando a desejar no quesito resistência mecânica. Não apresenta procedimentos analíticos de dimensionamento, simplificados ou não, de forma a considerar o critério de resistência mecânica no dimensionamento de paredes em alvenaria estrutural.

A norma europeia, das três avaliadas, é a mais completa. Apresenta procedimento tabular que leva em conta os três critérios de resistência ao fogo das paredes e mais um, o impacto mecânico nas paredes. Entretanto, possui algumas limitações quanto aos materiais de acabamento e nesse quesito não é tão completa quanto a norma americana. Apresenta também uma proposta de dimensionamento segundo método analítico que é bastante coerente, similar ao que já e feito para o concreto armado. O método em si não é complexo, porém, para utilizá-lo, são necessários resultados de ensaios em laboratório para determinar a distribuição de temperatura em um bloco em função do tempo de exposição ao fogo do mesmo. Existe a possibilidade, também, de determinação dessas isotermas do bloco por modelos numéricos feitos em softwares como Abaqus, Ansys, etc.

O código australiano leva em conta o índice de esbeltez da parede na verificação de sua resistência ao fogo, ou seja, é o único código, dentre os citados, que considera verdadeiramente tal aspecto. Entretanto, mais do que a constatação, o que se julgou deveras interessante foi o fato de que o uso dos ábacos fornecidos por fabricantes de blocos, baseados em resultados de ensaio das paredes em laboratório, tornou-se rapidamente intuitivo.

Sobre a aplicabilidade das normas internacionais à realidade brasileira, sabe-se que cada país possui especificações de geometria, capacidade resistente e espessura a serem respeitadas pela indústria de blocos estruturais. Além disso, existem variações, de país para país, das composições mineralógicas das rochas utilizadas como agregado e também dos revestimentos usuais. O que se sugere, portanto, é a elaboração de uma norma brasileira sobre o assunto que possa mesclar o que existe de mais interessante nas outras normas aqui apresentadas.

Inicialmente, por conta ainda do incipiente parque de equipamentos em laboratórios nacionais aptos à avaliação de paredes carregadas, ensaios de blocos isolados e com diferentes tipos de acabamentos podem ser realizados, para que tabelas semelhantes às americanas sejam elaboradas, de forma que se possam calcular estruturas de alvenaria em situação de incêndio considerando pelo menos o critério de isolamento térmico (I). Para conseguir isso, a melhor alternativa seria a união dos poucos laboratórios nacionais equipados para avaliar, em conjunto, todos os blocos usuais de nosso país.

Em seguida, o próximo passo seria o mapeamento das isotermas de todos os blocos usuais de nosso país. A simulação numérica é o caminho mais rápido e adequado para esse fim. Ressalta-se que, para o mapeamento de isotermas, é necessário a obtenção de inúmeras propriedades térmicas para os blocos usuais de nosso país, as quais seriam obtidas, também, no citado esforço conjunto entre os poucos laboratórios nacionais equipados para tal caracterização. Com isso, um método de cálculo simplificado semelhante ao do Eurocode 6 (EUROPEAN..., 2005), apresentado neste trabalho, poderia ser empregado para avaliação da resistência mecânica da parede $(\mathrm{R})$ em situação de incêndio.

Finalmente, ensaios de paredes de alvenaria, carregadas, em situação de incêndio deverão ser feitos, uma vez que, no país, é recente a instalação de um primeiro forno apto para tais ensaios (na UNISINOS, no Rio Grande do Sul), para que ábacos semelhantes aos australianos possam ser montados e assim, finalmente, serão reunidas informações suficientes para balizar uma primeira normatização nacional sobre o tema.

\section{Referências}

AMERICAN CONCRETE INSTITUTE.

ACI/TMS 216.1: code requirements for determining fire resistance of concrete and masonry construction assemblies. Michigan, 2014.

ANDREINI, M.; SASSU, M. Mechanical Behaviour of Full Unit Masonry Panels Under Fire Action. Fire Safety Journal, v. 46, n. 7, p. 440450, 2011.
ASSOCIAÇÃO BRASILEIRA DE CIMENTO PORTLAND; ASSOCIAÇÃO BRASILEIRA DA INDÚSTRIA DE BLOCOS DE CONCRETO. Alvenaria de Blocos de Concreto: guia para atendimento à Norma ABNT 15575. São Paulo, 2014. 
ASSOCIAÇÃO BRASILEIRA DA CONSTRUÇÃO INDUSTRIALIZADA. Manual Técnico de Alvenaria. São Paulo: A Associação, Projeto Editores Associados, 1990.

\section{ASSOCIAÇÃO BRASILEIRA DE NORMAS}

TÉCNICAS. NBR 14323: projeto de estruturas de aço e de estruturas mistas de aço e concreto de edifícios em situação de incêndio. Rio de Janeiro, 2013.

\section{ASSOCIAÇÃO BRASILEIRA DE NORMAS}

TÉCNICAS. NBR 14432: exigências de resistência ao fogo de elementos construtivos de edificações: procedimento. Rio de Janeiro, 2001.

\section{ASSOCIAÇÃO BRASILEIRA DE NORMAS}

TÉCNICAS. NBR 15200: projeto de estruturas de concreto em situação de incêndio. Rio de Janeiro, 2012.

\section{ASSOCIAÇÃO BRASILEIRA DE NORMAS}

TÉCNICAS. NBR 15270-2: componentes cerâmicos: blocos cerâmicos para alvenaria estrutural: terminologia e requisitos. Rio de Janeiro, 2005.

AUSTRALIAN STANDARD. AS 3700-2011: Masonry Structures. Sydney, 2011.

BAILEY, C. Structural Fire Design: core or specialist subject? The Structural Engineer, v. 82, n. 9, p. 32-38, 2004.

CONCRETE MASONRY ASSOCIATION OF AUSTRALIA. Part B, Chapter 4, Fire. In: CONCRETE MASONRY ASSOCIATION OF AUSTRALIA. Manual M55: design and construction of concrete masonry buildings. Australia, 2012.

BORAL MASONRY. Structural, Fire and Acoustics. In: BORAL MASONRY. Masonry Design Guide. Victoria, 2009. Book 1.

\section{BRICK INDUSTRY ASSOCIATION.}

Specifications for and Classification of Brick.

Disponível em:

<http://www.gobrick.com/portals/25/docs/technica 1\%20notes/tn9a.pdf>. Acesso em: 14 ago. 2015.

CHARALAMBIDES, J. E. Design of Masonry

Columns. Disponível em: <http://www.avantgarde-engineering.com/mc19.pdf $>$. Acesso em: 11 ago. 2015.

\section{EUROPEAN COMMITTEE FOR}

STANDARDIZATION. Eurocode 6: EN 2005-

1.2: design of masonry structures: part 1-2: general rules: structural fire design. Brussels, 2005.

INGHAM, J. Forensic Engineering of Fire-

Damaged Structures. ICE, v. 162, p. 12-17, 2009.

INTERNATIONAL ORGANIZATION FOR STANDARDIZATION. ISO 834-1: fireresistance tests: elements of building construction: part 1: general requirements. Geneva, 2015.

NADJAI, A. et al. Compartment Masonry Walls in Fire Situations. Fire Technology, v. 42, n. 3, p. 211-231, 2006.

NGUYEN, T. D.; MEFTAH, F. Behavior of Clay Hollow-Brick Masonry Walls During Fire: part 1: experimental analysis. Fire Safety Journal, v. 52, p. 55-64, 2012.

NGUYEN, T. D.; MEFTAH, F. Behavior of Hollow Clay Brick Masonry Walls During Fire: part 2: 3D finite element modelling and spalling assessment. Fire Safety Journal, v. 66, p. 35-45, 2014.

POLÍCIA MILITAR DO ESTADO DE SÃO PAULO, Corpo de Bombeiros. Instrução Técnica $n^{0}$ 08/2011: resistência ao fogo dos elementos de construção. São Paulo: Secretaria de Estado dos Negócios da Segurança Pública, 2011.

RIGÃO, A. O. Comportamento de Pequenas Paredes de Alvenaria Estrutural Frente a Altas Temperaturas. Santa Maria, 2012. 142 f. Dissertação (Mestrado em Engenharia Civil) Escola de Engenharia, Universidade Federal de Santa Maria, São Maria, 2012.

ROSEMANN, F. Resistência ao Fogo de Paredes de Alvenaria Estrutural de Blocos Cerâmicos pelo Critério de Isolamento Térmico. Florianópolis, 2011. 160 f. Dissertação (Mestrado em Engenharia Civil) - Escola de Engenharia, Universidade Federal de Santa Catarina, 2011.

TORRES, D. L. Alvenaria Estrutural em Situação de Incêndio: proposta de verificação. Campinas, 2012. 68 f. Qualificação (Mestrado em Engenharia Civil) - Escola de Engenharia, Universidade Estadual de Campinas, Campinas, 2012. 


\section{Helena Arias Lara Leite}

Faculdade de Engenharia Civil, Arquitetura e Urbanismo | Universidade Estadual de Campinas | Av. Albert Einstein, 951, Cidade Universitária Zeferino Vaz | Campinas - SP - Brasil | Caixa Postal 6021 | CEP 13083-852 | Tel.: (19) 3521-2363 Ramal 12363 | E-mail: helenaalleite@gmail.com

\section{Armando Lopes Moreno Junior}

Faculdade de Engenharia Civil, Arquitetura e Urbanismo | Universidade Estadual de Campinas | E-mail: almoreno@fec.unicamp.br

\section{Daniel Luis Torres}

Faculdade de Engenharia Civil, Arquitetura e Urbanismo | Universidade Estadual de Campinas | E-mail: dltorres@gmail.com

\section{Revista Ambiente Construído}

Associação Nacional de Tecnologia do Ambiente Construído

Av. Osvaldo Aranha, $99-3^{\circ}$ andar, Centro

Porto Alegre - RS - Brasil

CEP 90035-190

Telefone: +55 (51) 3308-4084

Fax: +55 (51) 3308-4054

www.seer.ufrgs.br/ambienteconstruido

E-mail: ambienteconstruido@ufrgs.br 